104 0. Helm, Prüfung d. Rosenöls. - O. Pape, Filtrat. schwer klärbar. Fluida.

\title{
Beitrag zur Revision der Pharmakopöe.
}

Prüfung des Rosenöls.

Von Otto Helm, Danzig.

Die deutsche Pharmacopöe schreibt behufs Prüfung des Rosenöls vor: Verdünnt man einen Theil Rosenöl mit fünf Theilen Chloroform und setzt dann zwanzig Theile Weingeist $\mathrm{zu}$, so scheiden sich Krystallflitter ab. Ich habe nun vier Proben Rosenöl, an deren Aechtheit und Reinheit zu zweifeln ich keinen Grund hatte, auf diese Weise untersucht. Es waren dies zwei Proben, welche direct von Ohmsen \& Comp. in Constantinopel bezogen waren und zwei aus bewährten deutschen Drogenhandlungen entnommene. Alle vier Proben schieden, in der vorbeschriebenen Weise behandelt, keine Krystallfitter ab. Ich halte deshalb die erwähnte Prüfungsmethode für eine irrthümliche.

\section{Filtration schwer klärbarer Fluida.}

Von O. Pape, Apotheker in Bremervörde.

Nach Einführung der Pharmakop. germanica Editio II., welche zum ersten Male Filtration der Syrupe verlangte, sind eine Reihe von Filtrirapparaten entstanden, welche theils ihrer Unbrauchbarkeit wegen nach einmaligem Gebrauche bei Seite gelegt, theils ihres hohen Preises wegen von kleineren Apotheken nicht angeschafft werden.

Es ist eine bekannte Thatsache, dass filtrirte Säfte in grossen Mengen nach monatelangem Stehen, wie Syr. ceras., Syr. rubi id. einen Bodensatz zeigen, wovon der grössere Theil des Syrups allerdings klar abgegossen werden kann, aber ein nicht geringer Theil mit dem Bodensatze ist ohne Klärung unbrauchbar. Filtration vermittelst Papierfilter lässt in diesem Falle sehr bald im Stiche, da das Filter in kurzer Zeit sich zusetzt.

Ein sehr einfaches und billiges Verfahren, welches stets zum Ziele führt, besteht darin, dass man etwa die Hälfte des zum Filter zu verwendenden Filtrirpapiers mit Wasser zu einem Brei anschlägt und die Masse auf einen Trichter bringt, dessen verengter Theil mit einem Pfropfen entfetteter Watte versehen ist. Für einen Trichter 
bis 20 Centimeter Durchmesser genügt eine Papierschicht von 3 bis 4 Centimeter Höhe; hierauf kann die Filtration des Syrups erfolgen.

Die wässrige Flüssigkeit wird durch das hohe specifische Gewicht eines Syrups schnell verdrängt, und ist zuerst zu entfernen; der dann durchlaufende Saft erscheint sehr bald klar. Dieses im Betreff der Syrupe.

Soll das Verfahren zur Klärung weiniger, spirituöser oder wässriger, pflanzlicher Auszüge, wie z. B. Infus. papaver., zu Syr. papaver. etc., welche oft durch Aufkochen und nachheriges Filtriren nicht zu klären sind, verwandt werden, bei weinigen oder spirituösen Auszügen darf eine Klärung durch Erhitzen überhaupt nicht stattfinden, so ist das anzuwendende Filtrirpapier mit dem weinigen, spirituösen oder wässrigen Auszuge zu einem Breie zu schlagen, und so $\mathrm{zu}$ verfahren, wie bei den Säften angegeben ist.

\section{B. Monatsberieht.}

\section{Pharmacentische Chemie.}

Zur Prifung des Natrium bicarbonicum. - H. Beckurts (Pharm. Centralh. 25, 589) hat die versohiedenen zum $Z$ wecke der Prüfung des Natriumbicarbonats auf einen Gehalt von Monocarbonat vorgeschlagenen und den Lesern des Archiv bekannten Methoden einer kritischen Bearbeitung unterzogen und ist dabei zu folgenden Resultaten gelangt:

1) Die Quecksilberchlorid - Probe nach der ursprünglichen Vorschrift von Bilt z liefert brauchbare Resultate und gestattet die Fixirung eines bestimmten Gehaltes an Monocarbonat. 2) Die Quecksilberchlorid-Probe der Pharmakopöe giebt ungleiche Resultate, da der wässerige mit Quecksilberchlorid zu versetzende Auszug des Salzes je nach der Beschaffenheit des Salzes und der Art der Bereitung verschiedene Mengen Mono- resp. Bicarbonat enthält. 3) Die Quecksilberchlorid - Probe der Pharmakopöe gestattet bei sachgemässer Ausführung nicht einmal einen Gehalt von 1 Proc. Monocarbonat, ist deshalb zu rigorös, da selbst bei Annahme eines im Handel vorkommenden von Monocarbonat freien Präparates das Salz in dem häufig zu öffnenden und geschüttelten, dem unmittelbaren Gebrauche dienenden Gefässe Kohlensäure verliert. 4) Die Phenolphtaleïn-Probe von $\mathrm{Kremel}^{1}$ zeigt einen Gehalt von 2 Proc. Monocarbonat sicher an und giebt brauchbare Resultate, wenn Ammonsalze abwesend sind. Aus der Intensität der Färbung kann man keinen Schluss auf die Menge des Monocarbonates ziehen, weshalb die Methode nie eine

1) Nach K. soll eine Natriumbicarbonatlösung, welche von Monocarbonat völlig frei ist, durch eine alkoholische Lösung von Phenolphtaleïn nicht gefärbt werden, während bei Gegenwart von Monocarbonat je nach der Menge desselben eine mehr oder woniger intensive Rothfärbang entsteht. 